\title{
Older Workers and Caregiving in a Global Context
}

\author{
Judith Phillips ${ }^{1} \cdot$ Kate O'Loughlin ${ }^{2}$
}

Published online: 11 July 2017

(C) Springer Science+Business Media, LLC 2017

\section{Editorial}

Population ageing is a global phenomenon whose impact on working age populations is only now being fully recognized and understood. Increased longevity, due to improved quality of life, advances in health, and better welfare provision, is generally accepted as a success story that will be ongoing with the expectation that populations worldwide will live to increasingly older ages (OECD 2012; WHO 2015). Governments around the world are now keenly focused on the social and economic challenges thrown up by population ageing. Some of the policy responses include encouraging older people to stay in the labour market, increasing the pension age, promoting self-funded retirement rather than reliance on a state pension, reducing entitlements to contain fiscal costs, and the introduction of personalised budgets or consumerdirected care in the provision of aged care services (Chomik and Piggott 2015; Gill and Cameron 2015; Chomik and Piggott 2012; Chomik and Whitehouse 2010).

There has been an increasing research focus on caregivers and recognition by governments (e.g. through flexible work arrangements) and policymakers of the contributions made by carers of all ages and at different stages of the life course, especially as more women are now in the workforce. However, there has been less of a focus on the pressures placed on older workers through the often competing demands of employment and care giving responsibilities, and the influence of these demands on their social and financial situation and health and wellbeing. Within economically developed countries these issues are brought into very sharp focus for the current cohort of post-WWII baby boomers, who are themselves moving into late middle age and into roles as multigenerational carers within the family (Mitchell 2015; Fingerman et al. 2012), while at the same time being expected to, or needing/wishing to,

Judith Phillips

judith.phillips@stir.ac.uk

Kate O'Loughlin

kate.oloughlin@sydney.edu.au

1 University of Stirling, Stirling, Scotland FK9 4LA, UK

2 Ageing, Work and Health Research Unit, Faculty of Health Sciences, University of Sydney,

Cumberland Campus, East Street, Lidcombe, NSW 2141, Australia 
remain in paid work. As a result of this, a key issue for policymakers is how people in later working life (itself extending to later ages) can provide care for, or otherwise support growing numbers of older people unable to be fully independent because of illness, disability or frailty, as well as their own adult children and possibly grandchildren. There is evidence to show that there are income and career penalties for carers (Warren 2015; Calvano 2013; Adair and Temple 2012; Fine 2012; Leigh 2010; Lero et al. 2007; Vlachantoni 2010; Bittman et al. 2007; Evandrou and Glaser 2003), and that where there are carer leave provisions they are not always adequate if the care required is ongoing (Hill et al. 2008).

Within the policy framework of 'positive ageing' found in most developed welfare states, there is a body of research addressing issues around the provision of both professional and family-related care for older people in various social and cultural contexts (see Kröger and Yeandle 2013; Fine 2012; Schroeder et al. 2012; Williams 2010; Bittman et al. 2007; Yeandle and Ungerson 2007), particularly as this relates to the concept of ageing in place. That is, as people age they will be supported to remain living in the community, as this is the preferred option of older people, their families and governments and provides a more cost-effective alternative to institutional care. There is now an increasing research focus on the consequences of such a policy approach for this distinct sub-group, older working carers, who are already facing unprecedented pressures to remain in and manage paid work alongside caring longer and more intensively for ageing (and other) family members and friends.

There is also a need to broaden the topic to address it as a global issue where countries can learn from each other. The distinctive contribution of this special issue is that it takes a global comparative perspective and draws on a range of methodological approaches. It adds value to the existing literature, updates policy debates in Western democratic countries and introduces new countries that are encountering these issues for the first time. Although many of the lessons and recommendations in these papers are not directly and easily transferable, there is utility in reviewing and comparing their care and work contexts, challenges and solutions.

\section{Existing Edited Collections and Special Issues}

The edited collections by Phillips (1995) and Liu and Kendig (2000) were amongst the first to recognise the impact of an ageing population and what this might mean for caregiving at the individual, family and government level. Both contributions focused on the concept of caregiving from an international perspective and articulated how it might be applied in different cultural contexts. Apart from these collections and the more recent edited collections by Martin-Matthews and Phillips (2008) and by Kröger and Yeandle (2013), little of the published empirical research on older carers has been brought together in a special issue. Kröger and Yeandle's edited collection provides an excellent overview and critical analysis of the policy provisions relevant to working carers in six countries and includes case studies reflecting the experiences of individual carers. The countries included represent three distinct welfare systems: public sector model (Sweden, Finland); liberal democracies (UK, Australia); family centred (Taiwan, Japan).

The Gerontologist special issue on Baby Boomers (Pruncho 2012) included 12 articles, four of which addressed aspects of the baby boomers as caregivers: comparison with earlier cohorts (Ryan et al. 2012); enduring intergenerational relationships with parents and adult children (Fingerman et al. 2012); boomers' expectations of support from paid service providers in 
balancing caregiving, work, family, and social life (Guberman et al. 2012); health status of this generation as caregivers (Hoffman et al. 2012).

Other recent special issues have looked at aspects of combining family and paid work, including caregiving, but generally with the focus on caring for younger children. A special issue in the Journal of Vocational Behavior on 'Career and work concerns of diverse and understudied workers', edited by Wendy Casper and Jennifer Swanberg (2011), included a paper on 'Eldercare demands, strain and work engagement: The moderating role of perceived organizational support' (Zacher and Winter 2011). The journal Community, Work \& Family has produced several special issues in recent years (see Nätti and Häikiö (2012)); Sweet 2011; Haar 2009; Bardoel and De Cieri 2009; Poelmans and Chenoy 2008) that canvassed key issues relevant to combining work and caring responsibilities, including the need for flexibility in the workplace and organisational support to meet these responsibilities, the changing demographic trend of women's increased participation in paid work, and the need for family friendly social policies. While these special issues also included an international perspective, provided comparative analyses, and recognised changing labour force practices in developed, developing, and newly industrialising countries, only one article specifically addressed issues (e.g. workplace flexibility) related to older workers and their caring responsibilities (PittCatsouphes and Matz-Costa 2008).

\section{Taking a Global Perspective}

This special issue brings together a group of international researchers and collection of papers that will make a significant contribution to scholarship around providing care within the family and community in the context of population ageing and specifically for those now entering late middle age. Analyses of how caregivers and policymakers function in different cultural contexts have much to offer to individual countries seeking effective solutions. The focus of our approach is that combining paid work and family caregiving for older workers is a reality of global demographic ageing, but the impact and policy response may be more or less developed (or absent) across different regions of the world. The countries included here represent a cross-section of developed (Australia, UK, New Zealand, Singapore), transitional (China) and developing countries (sub-Saharan Africa) with more or less established and stable welfare states. Within the context of population ageing all these countries are dealing with a range of sociocultural, economic and political imperatives that influence policy around providing care and support albeit with important national variations.

To date, the research focus on population ageing and its impact on labour market and welfare policies has been primarily on economically developed countries. A particular strength of this collection of papers is that while it includes some of these countries, it also brings in research from two widely varying countries in Asia and introduces a voice from less researched countries, notably sub-Saharan Africa. A common theme running through the papers is the centrality of family and, to some extent, the gendered nature of providing care for older members notwithstanding the level of development or material conditions. While it is common, there are again stark variations in how this translates into caring responsibilities and support for family carers: the liberal democracies (UK, Australia, New Zealand) provide carers' payments and have legislated to include forms of flexible work practices to accommodate family carers; in Singapore, notions of filial piety and family care may be mediated 
through the employment of foreign domestic workers to assist with caregiving (Mehta), while in China there is a strong reliance on family with little or no employer or public support for adult carers (Pei, Luo, Lin, Keating and Fast); and for sub-Saharan Africa, traditional family values are invoked in framing a reliance on the role of family in providing care rather than policies around formal care or support for carers (Aboderin and Hoffman). Each of the papers includes discussion of the effectiveness (or not) of policies in helping older carers combine care with paid work, recognition of the additional costs associated with caring, and reference to the health implications and stress that many older carers are likely to experience (Colombo et al. 2011).

\section{Methodological Contribution}

This special issue includes seven papers based on empirical analysis using quantitative and/or qualitative data to provide evidence of caregiving and work-related behaviours and outcomes for older workers (e.g. care histories, type and extent of care provided, early exit from paid work, working patterns/career outcomes, wage and pension differentials between care-givers and non-caregivers, health and well-being), and to deepen our understanding of the nexus between work and caregiving and its impact on ageing individuals, families and economies. A range of data sources was drawn on for the quantitative analyses including national (UK, New Zealand, Singapore), state-based (Australia) and regional city (China) survey data. For the Singapore and China studies, data from structured/semi-structured interviews were also included.

There are key contextual links in the evidence and analyses provided in the seven papers that revolve around responses to global demographic ageing and the need for ongoing and long-term care across generations. These include:

1. The post WW11 baby boomer cohort who are currently in mid to late life are at the forefront of global demographic, social and economic changes and are the ones facing unprecedented pressures to manage paid work and plan for retirement alongside caring longer and more intensively as multigenerational carers.

2. The potential disadvantages associated with unpaid caring responsibilities and the impact on workforce participation, financial security and health and well-being.

3. The expectation of continuity of family responsibilities for providing care and indeed governments' dependence on families to provide this care across the life course to contain costs and manage fiscal pressures on public funds.

4. Most research on caregiving indicates that overall a higher proportion of women than men provide unpaid care in households, and that women are more likely to be in the role of the primary carer which involves a higher level and intensity of caregiving (see Hosseinpoor et al. 2013; Vlachantoni 2010)). While there is evidence of the gendered nature of care in the country-based analyses included here, there is also some evidence that this trend could be changing through population ageing with older men becoming involved in caring for a spouse and/or ageing parents.

5. The dimension that provides both links and major contrasts is in policy and practice. While developed countries provide a policy framework that recognizes the contributions made by carers at different stages of the life course, including older working carers, the implementation and effectiveness of these policy initiatives is often uneven and lacks 
traction in terms of tangible outcomes for older workers (e.g. in individual workplaces). In contrast, social policies to provide support to family carers in China and sub-Saharan African countries are almost non-existent and the evidence suggests an urgent need to introduce policies and practices (e.g. workplace practices, improved pensions) that will reduce some of the pressures on older working carers as well as provide formal community support services for caregivers and care recipients.

The first paper (Kodate and Timonen) sets the scene for country comparisons on work and family life, couching the issue in the wider long-term and family care debates across European and Asian countries. Understanding the wider context and its often unintentional consequences for older workers and caregiving is crucial to formulating policy and practice at all levels of society.

The conclusions reached in our second paper illustrate many of the above aspects introduced by Kodate and Timonen. Yeandle and Buckner draw on new analysis from England to demonstrate growth in caring at higher levels of intensity and an increase in the incidence of carers who are also in paid employment despite policy advances in this area.

The effects of such increases, which are observed across the countries we address in this special issue, are seen on health, wellbeing and on living standards. These are picked up in the papers on New Zealand (Alpass and colleagues) and Australia (O'Loughlin, Loh and Kendig) where quality of life and more mobility difficulties are also reported.

These issues however are also being starkly experienced by countries in transition such as China and, as Pei and colleagues report, changes in the labour market are more likely to exacerbate the difficulties older workers face in juggling work and care unless policy responses are put in place. They are also experienced in more highly developed countries such as Singapore where Mehta, drawing on qualitative data, describes the increasing complexities when foreign domestic workers are introduced to address increasing stresses around juggling work and caregiving.

Finally, the paper on sub-Saharan Africa (Aboderin and Hoffman) provides an original contribution in assessing the limited empirical evidence available on long term care for dependent older adults in the region and provides a content analysis of key regional and selected national-level policy documents on ageing and its impact on families in Africa. The findings indicate the lack of formal care provisions, the reliance on care provided by family members, and the impact on the economic opportunities and health status of carers, especially on those already beset by poverty and lack of access to basic resources such as education, housing and transport. They identify the structural lag between long term care frameworks and the lived reality of care and provide a refreshing perspective on how these issues can be taken forward on the global stage.

The papers included in this proposal are authored by internationally recognised scholars from a range of disciplines resulting from collaborations forged through the Global Social Initiative on Ageing, a core activity of the International Association on Gerontology and Geriatrics, and further developed as the Older Workers and Caregiving project with funding support from the World Universities Network (Yeandle/University of Leeds; Fast/University of Alberta; O'Loughlin/University of Sydney). A key objective of the project is to build international comparative knowledge on older workers and caregiving, and establish an international collaborative network to work towards sustainability in policy-relevant population ageing research to inform global initiatives in socio-economic policies. It builds on the premise that population ageing and the erosion or absence of social welfare provisions, 
together with added pressures on working age populations, are imposing complex social and economic costs on family caregivers, paid care workers, workplaces, communities and governments around the world (Kendig and Lucas 2014; Kröger and Yeandle 2013; Keating et al. 2013). The authors and research focus of the papers included here are testimony to the success of this collaborative project.

This editorial would not be complete without our thanks to Editor-in-Chief of JCCG Margaret (Peggy) Perkinson for her patience and dedicated support in the production of this edition, the authors for their participation in various international meetings that resulted in the Special Issue, and also the support of the ARC Centre of Excellence in Population Ageing Research (CEPAR), the Worldwide Universities Network (WUN) member universities (Alberta, Leeds, Sheffield, Sydney) and the IAGG's Global Social Initiative on Ageing (GSIA).

Kate O'Loughlin and Judith Phillips

\section{References}

Adair, T., \& Temple, J. (2012). Barriers to mature age labour force engagement in Australia: Report on the 2011-12 national survey on the barriers to employment for mature age people. Canberra: National Seniors Productive Ageing Centre.

Bardoel, A., \& De Cieri, H. (Eds.). (2009). Community and work-life issues in a global context: New perspectives in a changing world. Community, Work \& Family, 12(2), 141-142.

Bittman, M., Hill, T., \& Thomson, C. (2007). The impact of caring on Informal Carers' employment, income and earnings: A longitudinal approach. Australian Journal of Social Issues, 42, 2.

Calvano, L. (2013). Tug of war: Caring for our elders while remaining productive at work. The Academy of Management Perspectives, 27(3), 204-218.

Casper, W. J., \& Swanberg, J. E. (2011). Career and work concerns of diverse and understudied workers. Journal of Vocational Behavior, 79(3), 611-612.

Chomik, R., \& Piggott, J. (2012). Mature-age labour force participation: Trends, barriers, incentives, and future potential. CEPAR research brief 2012/01.

Chomik, R., \& Piggott, J. (2015). Population Aging and social security in Asia. Asian Economic Policy Review, 10(2), 199-222.

Chomik, R., \& Whitehouse, E. R. (2010). Trends in Pension Eligibility Ages and Life Expectancy, 1950-2050, OECD Social, Employment and Migration Working Papers, No. 105, OECD Publishing. doi:10.1787 $15 \mathrm{~km} 68 \mathrm{fzhs} 2 \mathrm{q} 4-\mathrm{en}$.

Colombo, F., Llena-Nozal, A., Mercier, J., \& Tjadens, F. (2011). Help wanted? Providing and paying for long term Care, OECD Publishing.

Evandrou, M., \& Glaser, K. (2003). Combining work and family life: The pension penalty of caring. Ageing and Society, 23(5), 583-601.

Fine, M. (2012). Employment and Informal care: Sustaining paid work and caregiving in community and homebased care. Ageing International, 37, 57-68.

Fingerman, K., Pillemer, K., Silverstein, M., \& Suitor, J. (2012). The baby boomers' intergenerational relationships. The Gerontologist, 52(2), 199-209.

Gill, L., \& Cameron, I. (2015). Innovation and consumer directed care: Identifying the challenges. Australasian Journal on Ageing, 34(4), 265-268.

Guberman, N., Lavoie, J.-P., Blein, L., \& Olazabal, I. (2012). Baby boom caregivers: Care in the age of individualization. The Gerontologist, 52(2), 210-218.

Haar, J. (Ed.). (2009). An international perspective on work-family. Community, Work \& Family, 12(3), $275-277$.

Hill, T., Thomson, C. M., Bittman, M. P., \& Griffiths, M. J. (2008). What kinds of jobs help carers combine care and employment? Family Matters, 80, 27-32.

Hoffman, G., Lee, J., \& Mendez-Luck, C. (2012). Health behaviors among baby boomer Informal caregivers. The Gerontologist, 52(2), 219-230.

Hosseinpoor, A. R., Bergen, N., \& Chatterji, S. (2013). Socio-demographic determinants of caregiving in older adults of low- and middle-income countries. Age and Ageing, 42, 330-338.

Keating, N., Lero, D. S., Fast, J., Lucas, S., \& Eales, J. (2013). A framework and literature review on the economic costs of care. Centre for Families, work \& wellbeing, University of Guelph and research on Aging, 
policies, and practice, Department of Human Ecology, University of Alberta. https:/www.researchgate. net/publication/236035911

Kendig, H., \& Lucas, N. (2014). Individuals, families and the state: Changing responsibilities in an ageing Australia. In A. Torres \& L. Samson (Eds.), Aging in Asia-Pacific: Balancing the State and the Family (pp. 211-224). Diliman: Philippine Social Science Council (PSSC).

Kröger, T., \& Yeandle, S. (Eds.). (2013). Combining paid work and family care: Policies and experiences in international perspective. Bristol: Policy Press.

Leigh, A. (2010). Informal care and labor market participation. Labour Economics, 17, 140-149.

Lero, D., Keating, N., Fast, J., Joseph, G., \& Cook L. (2007). The Interplay of Risk Factors Associated with Negative Outcomes among Family Caregivers: A Synthesis of the Literature. Human Resources and Skills Development Canada.

Liu, W., \& Kendig, H. (Eds.). (2000). Who should care for the elderly: An east-west divide. Singapore: Singapore University Press/World Scientific.

Martin-Matthews, A., \& Phillips, J. E. (Eds.). (2008). Aging and Caring at the Intersection of Work and Home Life. Blurring the Boundaries. New York: Taylor and Francis.

Mitchell, B. A. (2015). Intergenerational and family ties of baby boomers. The Encyclopedia of Adulthood and Aging, 1-5. doi: 10.1002/9781118521373.wbeaa291.

Nätti, J., \& Häikiö, L. (Eds.). (2012). Flexible work and work-family interaction. Community, Work \& Family, 15(4), 381-382.

OECD (2012). Looking to 2060: Long-term global growth prospects. OECD Economic Policy Papers No.3. Paris: OECD Publishing.

Phillips, J. (Ed.) (1995). Working Carers. Aldershot: Avebury.

Pitt-Catsouphes, M., \& Matz-Costa, C. (2008). The multi-generational workforce: Workplace flexibility and engagement. Community, Work \& Family, 11(2), 215-229.

Poelmans, S., \& Chenoy, R. (2008). Investigating workplace flexibility using a multi-organization database: A collaboration of academics and practitioners. Community, Work \& Family, 11(2), 133-137.

Pruncho, R. (Ed.). (2012). Not your Mother's Old Age: Baby Boomers at 65. Special Issue, The Gerontologist 52(2), Oxford: Oxford University Press.

Ryan, L. H., Smith, J., Antonucci, T. C., \& Jackson, J. S. (2012). Cohort differences in the availability of Informal caregivers: Are the boomers at risk? The Gerontologist, 52(2), 177-188.

Schroeder, B., MacDonald, J., \& Shamian, J. (2012). Older workers with caregiving responsibilities: A Canadian perspective on corporate caring. Ageing International, 37, 39-56.

Sweet, S. (Ed.). (2011). Anticipated and unanticipated consequences of work family policy: Insights from international comparative analyses. Community, Work \& Family, 14(2), 117-118.

Vlachantoni, A. (2010). The demographic characteristics and economic activity patterns of carers over 50: Evidence from the English longitudinal study of ageing, Population Trends, nr 141(Autumn), 1-23.

Warren, D. (2015). Pathways to retirement in Australia: Evidence from the HILDA survey. Work, Aging and Retirement, 1(2), 144-165.

Williams, F. (2010). Claiming and framing in the making of care policies: The recognition and redistribution of care. Geneva: United Nations Research Institute for Social Development.

World Health Organization (WHO) (2015). World Report on Ageing and Health 2015. Geneva: WHO.

Yeandle, S., \& Ungerson, C. (Eds.). (2007). Cash for Care in Developed Welfare States. London: Palgrave Macmillan.

Zacher, H., \& Winter, G. (2011). Eldercare demands, strain and work engagement: The moderating role of perceived organizational support. Journal of Vocational Behavior, 79, 667-680. 